\title{
ROODAPLAYER: UM TOCADOR DE MÍDIA INTEGRADO A UM AMBIENTE VIRTUAL DE APRENDIZAGEM
}

\author{
Patricia Alejandra Behar - UFRGS/NUTED - patricia.behar@ufrgs.br \\ Fátima Weber Rosas - UFRGS/NUTED - fwrosas@ gmail.com \\ Magalí Teresinha Longhi - UFRGS/NUTED - mlonghi@ cesup.ufrgs.br \\ Maira Bernardi - UFRGS/NUTED - mairaber@ terra.com.br
}

\begin{abstract}
Resumo: Este artigo apresenta um tocador de mídias digitais integrado ao ambiente virtual de aprendizagem (AVA) ROODA. São apresentadas as etapas de sua construção e as possibilidades pedagógicas, coletadas através de um questionário on-line submetido a professores, tutores e desenvolvedores de objetos de aprendizagem. Também é abordada a utilização de podcasting, audiocasting e videocasting como uma das potencialidades pedagógicas de um tocador de mídias digitais integrado a AVAs. Trata-se, ainda, da produção e utilização de áudios e vídeos na educação à distância (EAD) de modo a potencializar a dimensão afetiva e a cognitiva.
\end{abstract}

Palavras-chave: Ambiente virtual de aprendizagem, tocador de mídias digitais, podcasting.

\begin{abstract}
This paper presents a digital media player integrated with the virtual learning environment (VLE) ROODA. It presents the stages of its construction and the educational possibilities of their use. For these we had collected data from an online questionnaire which wet sent it to teachers, tutors, and developers of learning objects. Also, the paper cover the use of podcasting, audiocasting, and videocasting as one of the pedagogical possibilities of a digital media player integrated with VLEs. It shows the production and use of audio and video in distance learning (DL) to enhance the affective and cognitive dimension.
\end{abstract}

Keywords: Virtual learning environment, digital media player, podcasting.

\section{INTRODUÇÃO}

O sucesso de um curso a distância depende da adequação dos materiais didáticos e de um modelo pedagógico embasado solidamente numa epistemologia. A qualidade de cursos a distância deve primar pelo caráter intelectual do conteúdo. Tal qualidade pressupõe o estímulo a múltiplas possibilidades de interação e de motivação.

As Tecnologias de Comunicação e de Informação (TICs), ao contribuírem para interação entre os sujeitos envolvidos na EAD, podem potencializar a aprendizagem. Nesse contexto a produção de material educacional digital (MED) deve estar em consonância com a fundamentação epistemológica e pedagógica do curso. De fato, ao se enfatizarem as interações, a tecnologia assegura condições para a construção mais efetiva do conhecimento, extrapolando, desse modo, sua mera função transmissiva. Ao disponibilizar em MEDs recursos tecnológicos, tais como o audiovisual e ou quaisquer outros disponíveis na Web, dão-se condições ao sujeito para que se torne mais ativo no processo de aprendizagem. 
Uma das alternativas para o aprimoramento dos cursos a distância consiste no desenvolvimento de novas ferramentas direcionadas aos AVAs que suportem recursos de videocasting, audiocasting e podcasting. Diante do massivo uso de arquivos em formato mp3 e de vídeos na Internet, surge a possibilidade do emprego de áudio e vídeo como função educativa. Dessa maneira o audiovisual assume a forma de materiais digitais multimídias, integrando sons, imagens, textos e animações. O uso de podcasting e videocasting, em termos educacionais, vem sendo utilizado em larga escala em nível nacional e internacional, desde a Escola Básica até o Ensino Superior. O intuito de tal emprego é explorar o potencial pedagógico do áudio, do vídeo e de outras mídias incorporadas a esses.

Com a finalidade de facilitar a utilização de áudios e vídeos nas aulas virtuais, foi desenvolvido um tocador de mídias digitais integrado a um AVA, intitulado ROODAPlayer ${ }^{1}$. Através desse tocador, entende-se que é ampliada a possibilidade da produção e utilização pedagógica do podcasting, audiocasting e videocasting na EAD.

\section{O ROODAPLAYER}

O ROODAPlayer é uma funcionalidade do AVA ROODA que serve como um tocador de mídias digitais integrado. O ROODA, Rede cOOperativa De Aprendizagem ${ }^{2}$ (Figura 1), é um AVA que foi desenvolvido em 2000, dentro da ideia de software livre. Esse ambiente disponibiliza ferramentas para a interação e a comunicação síncrona e assíncrona, valorizando o trabalho cooperativo. Sua construção foi baseada numa concepção epistemológica interacionista (Piaget, 1973). Esse AVA tem como características favorecer a interação, a aprendizagem enquanto processo individual e coletivo, a comunicação assíncrona e síncrona, bem como a interdisciplinaridade, a hipertextualidade e o trabalho em equipe (Behar, et al, 2007).

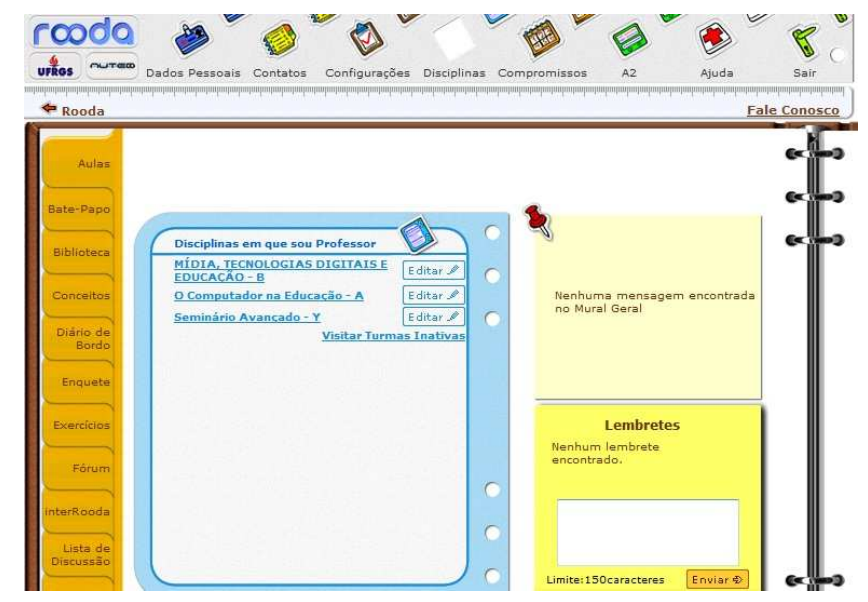

Figura 1 - Tela inicial do ROODA após login

A principal vantagem da integração do ROODAPlayer (Figura 2) nesse ambiente consiste na facilidade de acesso a áudios e vídeos, não necessitando a instalação de vários aplicativos externos para a exibição dos mesmos. Dessa maneira, existe a possibilidade de integrá-los com maior naturalidade aos conteúdos e proposta dos professores. Assim, professores e alunos podem produzir seus próprios vídeos e/ou arquivos de áudio e disponibilizá-los através dessa funcionalidade. 


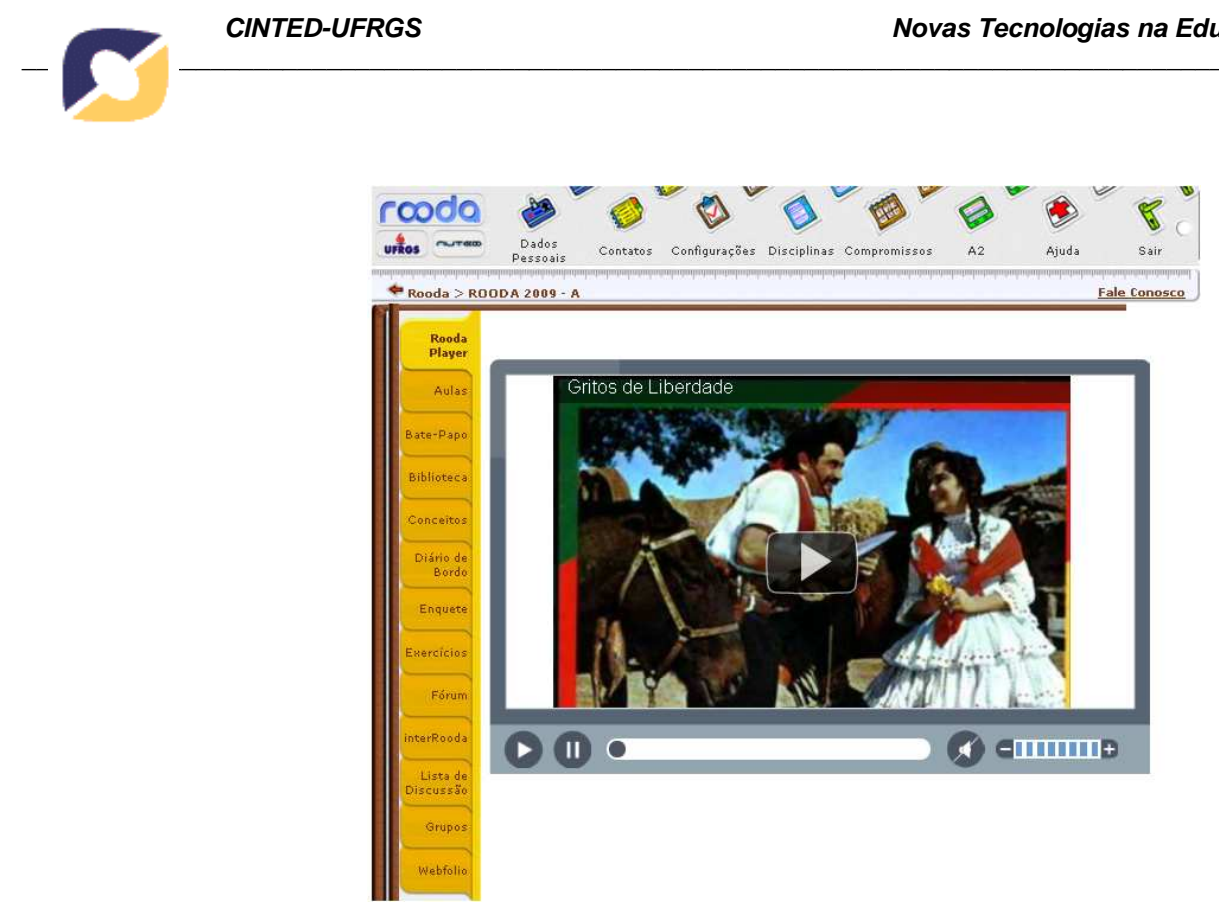

Figura 2 - ROODAPlayer

Para o desenvolvimento do ROODAPLayer, foram previstos estudos de players do mercado (livres e proprietários); avaliação de uso de servidores públicos ou não; design da nova funcionalidade, considerando os padrões atuais do ROODA; implementação, testes de operacionalidade, validação da nova funcionalidade em disciplinas de graduação e pós-graduação e disponibilização na plataforma oficial.

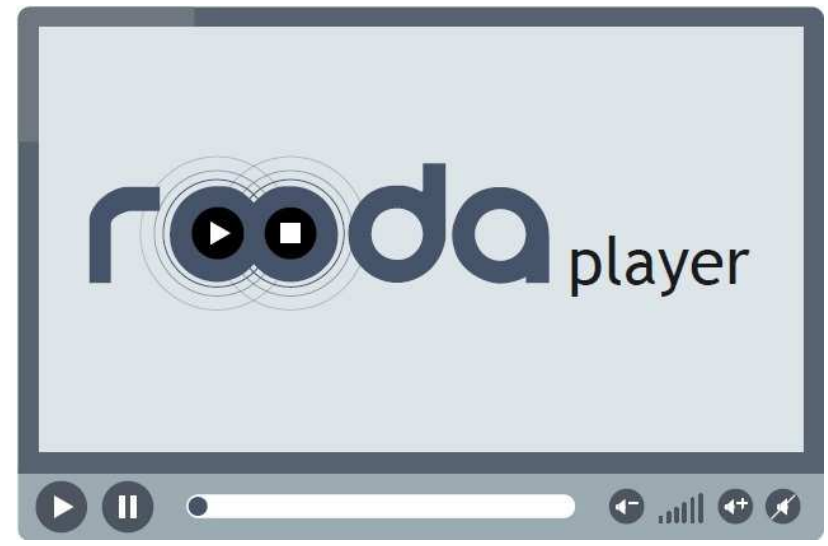

Figura 3 - Design do ROODAPlayer

Além dos estudos de players do mercado pesquisou-se e testaram-se diversos websites que poderão servir como hospedeiros de arquivos de áudio e vídeo, do tipo podcast. São eles: Podomatic (http://www.podomatic.com), Podcast One (http://www.podcast1.com.br/), e Mypodcast (http://www.mypodcast.com/). A vantagem do uso de podcasting é que, além da possibilidade dos arquivos mp3 serem escutados no ROODAPlayer, também poderão ser escutados ou baixados em iPods, celulares, iPhones e outros similares que permitam a sua assinatura. Há, também, a possibilidade de integração de áudio, texto, imagens e vídeos, porém os vídeos necessitam ser postados em servidores, a exemplo do Youtube (http://www.youtube.com). Cada um desses websites possui suas particularidades. Foram feitos testes com vários websites e decidiu-se, neste momento, pelo Youtube.

No decorrer do desenvolvimento dessa funcionalidade, foram realizadas pesquisas sobre a utilização pedagógica do ROODAPlayer, resultando na aplicação de um 
questionário on-line. $\mathrm{O}$ questionário foi disponibilizado no Google Docs e teve o objetivo de coletar dados sobre as possibilidades pedagógicas desta nova funcionalidade, com público-alvo voltado para professores, tutores utilizadores de AVAs e desenvolvedores de objetos de aprendizagem.

\section{POTENCIALIDADES PEDAGÓGICAS DO ROODAPLAYER: AUDIOCAST E PODCAST}

Uma das possibilidades pedagógicas do ROODAPlayer é sua integração com podcasting e/ou vodcasting. "Podcasting é um processo mediático baseado em emissões sonoras que utiliza a Internet como suporte para seu funcionamento $e$ propagação de suas mensagens" (Bottentuit Junior, et al, 2009, p.294). O vodcast ou videocast é semelhante ao podcast, porém possibilita a distribuição não somente de áudio, mas também de vídeo. De acordo com Carvalho (et al, 2009) os videocasts começaram a surgir em 2005 com função de entretenimento e somente mais tarde, em 2007 começaram a ser utilizados no contexto educacional. (Bottentuit Junior, et al, 2009), (Carvalho, et al, 2009). Neste trabalho, ao se referir a podcasting, se estará referindo ao processo como um todo, englobando produção de podcast e videocast.

Através dessa funcionalidade, docentes e discentes podem acessar podcasts e vodcasts, abrindo-os no próprio AVA, sem precisar acessar links externos. O podcasting pode ser produzido pelo professor ou tutor, ou pode ser solicitado aos alunos que o criem de acordo com o conteúdo e proposta do professor. Basta fazer upload desses arquivos em algum website hospedeiro de áudio e/vídeo.

McLoughlin e Lee (2007) ao falarem do podcast no Ensino Superior, diferem o termo de audiocast. Embora o termo podcast seja utilizado por diversos autores e educadores como sendo um arquivo de áudio transmitido via Internet, para McLoughlin e Lee (Ibid.) essa definição seria a de audiocast. A principal diferença entre eles seria a ausência de periodicidade. Entretanto, acredita-se que ambos possam servir de apoio pedagógico, influenciando a dimensão afetiva e cognitiva do sujeito.

Diferentemente do audiocast, o podcast conta com mais dois elementos para o seu funcionamento, além do arquivo de áudio, em geral no formato mp3. São eles o RSS Feed (Really Simple Syndication ou Distribuição Realmente Simples) correspondente e o agregador de conteúdos. O termo podcast surgiu com a união das palavras iPod (dispositivo de armazenamento de áudio da Apple) e cast, abreviatura de broadcast que significa transmissão em larga escala. O RSS Feed permite que o utilizador seja notificado por e-mail sempre que o podcast subscrito é atualizado, não tendo de consultá-lo, mas estando sempre a par das atualizações feitas pelos podcasters (Cruz, 2009).

O podcast possui episódios em formato digital com periodicidade regular. A tecnologia RSS Feed permite uma comunicação multidirecional para público diverso, permitindo o download de arquivos em formato $\mathrm{mp} 3, \mathrm{mp} 4$ ou ogg e pode ser utilizado tanto como micro mídia quanto mídia de nicho. "A mídia de nicho trabalha no sentido de produzir conteúdo para um público alvo bem segmentado, cujo perfil é avaliado através de constantes pesquisas de marketing. [...] as condições de produção da mídia de nicho assemelham-se mais às da mídia de massa" (Primo, 2005, p.3;17).

Diferente da Web Rádio ou rádio on-line, o tempo de produção e publicação do podcasting não coincide com o tempo da escuta. Segundo Primo (2005) essa propriedade possibilita novas formas de interação. Diferentemente das tradicionais mídias de nicho como rádios comerciais e televisão, os podcasts atingem públicos pequenos, mas que são interconectados entre si. A possibilidade dos internautas 
associarem um podcast a redes sociais como twitter, facebook, Orkut, blogs, fóruns e outros, contribui para a divulgação e debate do que foi lido/escutado em outros lugares na rede. "A dispersão e capilaridade dessa interação horizontalizada na Internet favorece a propagação de informações, amplificando o debate no que toca o seu alcance e conteúdo (por vezes acrescentando novos elementos ou mesmo suprimindo outros." (Primo, 2005, p.10;17).

Por isso, acredita-se que essas tecnologias possam ser ampliadas na EAD através da sua integração em AVAs. Um exemplo disso é a integração do tocador de mídias digitais, denominado como ROODAPlayer, ao ambiente ROODA.

\section{PODCASTING E AUDIOCASTING: UM OLHAR A PARTIR DOS ASPECTOS AFETIVOS E COGNITIVOS}

Gonzalez (2009) afirma que os projetos educacionais que envolvem recursos de áudio têm produzido impactos favoráveis no processo de aprendizagem. Um exemplo disso são as rádios-pátio (mesa de som, tocador de CDs, microfone e caixas de som), muito utilizadas nas escolas ou mesmo projetos mais sofisticados que envolvem o uso do computador. Segundo o autor, esses recursos envolvendo o áudio têm produzido impactos visíveis no processo de aprendizagem, como a animação e o entusiasmo com que os alunos e professores se envolvem colaborativamente na produção de programas educativos como áudio-aula ou vídeo-aula. $\mathrm{O}$ autor também menciona que a Internet é uma poderosa mídia digital de baixo custo, facilitadora de distribuição de informação audiovisual e textual, abrindo inúmeras alternativas educativas.

Para Piaget (2005) a cognição e a afetividade não podem ser dissociadas no processo de construção do conhecimento. A afetividade é o agente dinamizador de uma ação e favorece o raciocínio, fator fundamental à aprendizagem.

Marques (2009) entende que o ato da fala expressa emoções. Ao realizar as primeiras reflexões sobre os sons, a autora destaca a obra Retórica de Aristóteles. Nessa obra, o autor enfatiza a Poética que, por sua vez, considera três características fônicas: o volume da voz, a entoação e o ritmo que modelam a fala de forma que se expresse também, emoções por meio dela. Dessa maneira, tanto no podcast como no audiocast, a voz estabelece relações com a memória discursiva dos alunos e a afetividade.

Por outro lado, Cardoso (1997) sustenta que o podcast convoca a memória auditiva que, por sua vez, está ligada à aprendizagem. Sabe-se que a memória possui estreita ligação com a mesma e que uma experiência prazerosa ajuda um conteúdo a permanecer na memória a longo-prazo. Também é fato que há um mecanismo de defesa que impede as experiências ruins de irem para a memória a longo-prazo. Por esse motivo toda a aprendizagem deve ser realizada em ambiente descontraído.

Hardgreaves (1999) concorda com o potencial motivador de tecnologias musicais digitais ao promover uma aprendizagem que faça sentido ao educando. Segundo ele, os jovens são utilizadores ávidos de celulares, players de mp3, mp4 e outros dispositivos móveis e tendem a passar mais tempo ouvindo música do que fazendo outras atividades. Como a música está presente no cotidiano desses jovens, e também de adultos, entendese que sua presença através de audiocast, podcasting e/ou videocasting, também possa levar a uma aprendizagem significativa, tanto na educação presencial, semipresencial como na totalmente à distância.

Rosas e Behar (2010), ao se referirem à música presente no contexto educacionaldigital, acreditam que se deve dar atenção às propriedades extramusicais. Tais propriedades embora não sejam musicais, procedem destas, como altura, timbre, tempo, 
ritmo, etc. Dentre aquelas que não são musicais, destaca-se a comunicação de emoções, que está relacionada à afetividade, mais precisamente ao que concerne aos estados de ânimo do aluno. De forma semelhante como é feita para o cinema, a música na educação deve atingir o público-alvo como elemento motivador. Dessa forma, a dimensão afetiva também está envolvida no planejamento e uso de recursos com trilhas sonoras, como materiais educacionais digitais, vídeos, audiocast e podcasting.

\section{RESULTADOS E ANÁLISES DOS RESULTADOS DO QUESTIONÁRIO}

Durante o desenvolvimento do ROODAPlayer foi realizado e aplicado um questionário on-line intitulado: "Tocador ou Player de mídias em um AVA". Esse questionário teve o objetivo de coletar dados sobre as possibilidades da sua utilização em cursos e disciplinas semipresenciais e à distância por professores, tutores e desenvolvedores de objetos de aprendizagem. Este formulário foi enviado a professores, tutores e equipes desenvolvedoras de objetos de aprendizagem, por meio de uma lista de correio eletrônico da Secretaria de Educação à Distância (SEAD).

O questionário foi dividido em duas partes. A primeira parte apresentou nove questões buscando informações sobre o público-alvo, como por exemplo, área de atuação, cursos ou disciplinas ministradas, função (desenvolvedor, professor ou tutor), bem como preferências na utilização de áudios e vídeos em aulas à distância, etc. Dentre os dados coletados, as áreas de atuação encontradas foram: Odontologia, Música (presencial e à distância), Saúde e Rede Gaúcha de Ensino Superior à Distância (REGESD). O público-alvo contemplou $60 \%$ professores, $20 \%$ tutores e $20 \%$ desenvolvedores. Os AVAs mais utilizados foram o ROODA e o MOODLE. Dentre as multimídias mais utilizadas foram: vídeos, Power Point, arquivos de áudio, iTunes, Windows Media Player, Real Player. A maioria não utilizava áudios nas aulas, mas sim, vídeos.

A segunda parte teve sete questões baseadas na escala de Likert. Foi apresentado o seguinte enunciado: Se você tivesse um tocador de mídias (player de áudio e vídeo) integrado ao seu AVA, assinale, numa escala de 1 a 5, sendo: 1- Concordo plenamente; 2- Concordo; 3-Discordo; 4- Discordo plenamente; 5- Nenhuma resposta.

TABELA 1 - Resultados do questionário

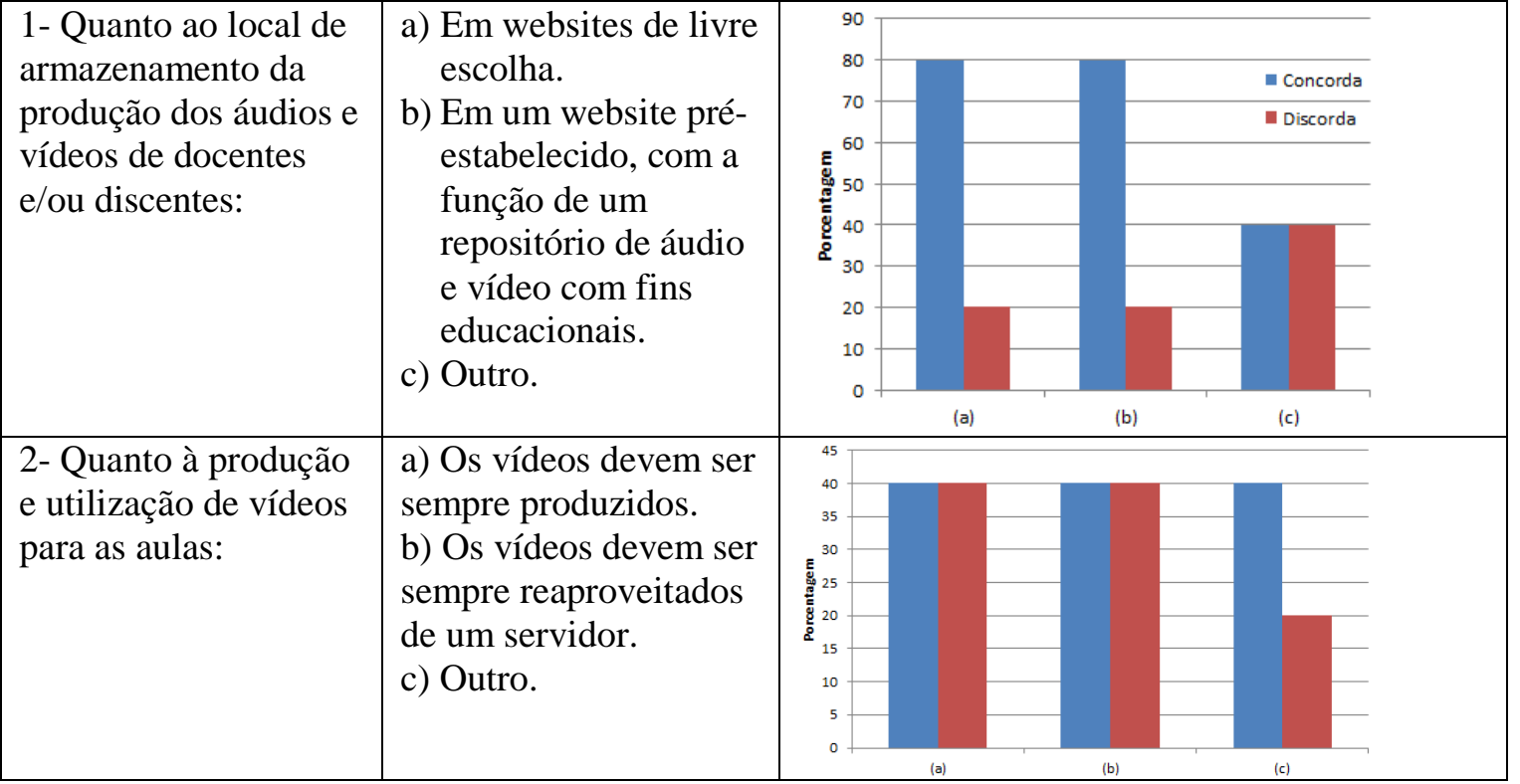




\begin{tabular}{|c|c|c|c|c|c|c|c|c|}
\hline $\begin{array}{l}3 \text { - Quanto à produção } \\
\text { ou reaproveitamento } \\
\text { de áudios: }\end{array}$ & $\begin{array}{l}\text { a) Os áudios devem ter } \\
\text { uma parte com } \\
\text { produção própria e } \\
\text { outra com trechos } \\
\text { reaproveitados. } \\
\text { b) Os áudios devem ser } \\
\text { sempre reaproveitados } \\
\text { de um site ou } \\
\text { repositório. } \\
\text { c) Os áudios devem ser } \\
\text { produzidos ou } \\
\text { compostos com autoria } \\
\text { própria na sua íntegra. } \\
\text { d) Outro }\end{array}$ & 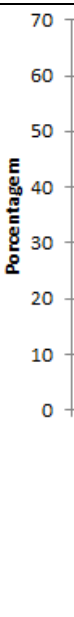 & (a) & (b) & (c) & & (d) & \\
\hline $\begin{array}{l}4 \text { - Quanto aos atores } \\
\text { produtores dos } \\
\text { vídeos: }\end{array}$ & $\begin{array}{l}\text { a) Devem ser } \\
\text { produzidos somente } \\
\text { pelos professores. } \\
\text { b) Devem ser } \\
\text { produzidos por } \\
\text { professores e tutores. } \\
\text { c) Devem ser } \\
\text { produzidos somente } \\
\text { pelos tutores. } \\
\text { d) Devem ser } \\
\text { produzidos pelos } \\
\text { tutores e pelos alunos. } \\
\text { e) Devem ser } \\
\text { produzidos somente } \\
\text { pelos alunos. } \\
\text { f) Devem ser } \\
\text { produzidos por } \\
\text { professores, tutores e } \\
\text { alunos. } \\
\text { g) Devem ser } \\
\text { reaproveitados. }\end{array}$ & 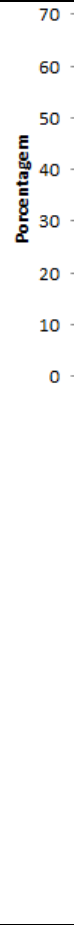 & $\begin{array}{lll} & \text { (b) }\end{array}$ & (c) & 4) & (e) & (f) & (g) \\
\hline $\begin{array}{l}5 \text { - Quanto aos atores } \\
\text { produtores dos } \\
\text { arquivos de áudio: }\end{array}$ & $\begin{array}{l}\text { a) Devem ser } \\
\text { produzidos somente } \\
\text { pelos professores. } \\
\text { b) Devem ser } \\
\text { produzidos pelos } \\
\text { professores e tutores. } \\
\text { c) Devem ser } \\
\text { produzidos somente } \\
\text { pelos tutores. } \\
\text { d) Devem ser } \\
\text { produzidos pelos } \\
\text { tutores e pelos alunos. } \\
\text { e) Devem ser } \\
\text { produzidos somente } \\
\text { pelos alunos. } \\
\text { f) Devem ser } \\
\text { produzidos por } \\
\text { professores, tutores e } \\
\text { alunos. } \\
\text { g) Devem ser }\end{array}$ & 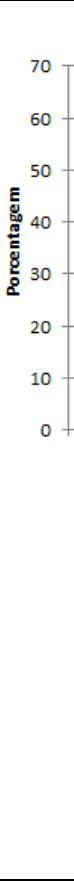 & $\begin{array}{ll}\text { (a) } & \text { (b) }\end{array}$ & (c) & (d) & & (f) & $\frac{}{\text { (g) }}$ \\
\hline
\end{tabular}




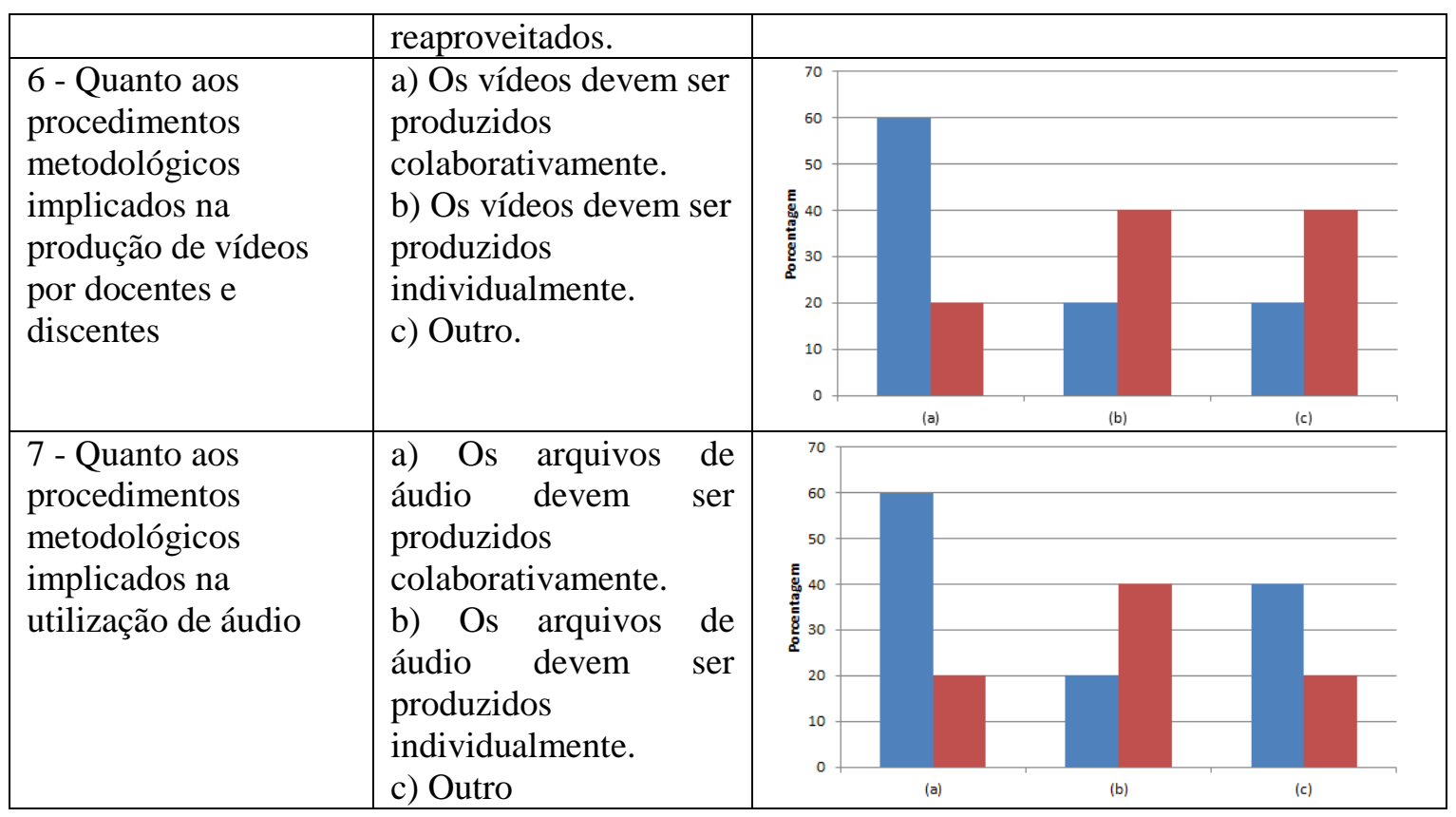

Quanto aos arquivos de vídeo, ao se analisar os resultados do questionário (Tabela 1) conclui-se, pela maioria das respostas, que esses devam ser postados em websites pré-estabelecidos, produzidos com trechos reaproveitados e com trechos de autoria própria de maneira colaborativa por professores, tutores e alunos. Sobre os arquivos de áudio, a maioria das respostas foi a favor que esses devam ser produzidos por professores, tutores e alunos, dependendo da situação e armazenados em websites préestabelecidos com uma parte reaproveitada e outra(s) com criação própria. Ao abordar o aspecto colaborativo da produção de arquivos de áudio, os sujeitos responderam que dependeria do contexto e/ou da necessidade de aplicação desses arquivos.

\section{CONCLUSÕES}

A partir deste estudo, pode-se dizer que, dentre as vantagens de um tocador de mídias integrado a um AVA, destaca-se a produção de vídeos inéditos por docentes e discentes, com seus respectivos áudios, incluindo música e a utilização de podcast/videocast/audiocast nas aulas virtuais. O podcast, o audiocast e o videocast podem ser importantes elementos motivadores no processo de aprendizagem, pois permitem conter a expressividade vocal e/ou facial que um texto digitalizado um impresso não contém, sem falar da possibilidade de conter trilha sonora com música motivadora, influenciando nos estados de ânimo dos sujeitos.

A produção de áudios e vídeos e também de podcasting pelos alunos pode desenvolver competências, principalmente aquelas ligadas à oralidade. Especialmente na produção de podcasting, os alunos envolvem-se na organização, roteiro, pré e pósplanejamento, ampliando outras habilidades, além da comunicação. Quando há inserção de trilha sonora, também há o desenvolvimento de habilidades ligadas à música.

A música digital está presente no cotidiano de jovens na Internet em diversos dispositivos portáteis. Na busca por uma aprendizagem mais significativa, a música pode se tornar um importante elemento de apoio à Educação. Por meio das ferramentas livres de produção e edição de áudio, é possível que docentes e discentes produzam suas próprias trilhas sonoras para materiais educacionais digitais.

Através da análise dos resultados obtidos através do questionário on-line sobre tocadores de mídias integrados em AVAs, pode-se concluir que o ROODAPlayer pode 
vir a auxiliar no processo de aprendizagem. Muitos professores, tutores e equipes desenvolvedoras de objetos de aprendizagem recorrem a materiais de áudio e vídeo em suas aulas, ou no desenvolvimento de MEDs. Conforme registrado no questionário, aqueles que ainda não utilizam esses dispositivos possuem interesse em empregá-los.

Expôs-se aqui, as funções de um tocador de mídias digitais integrado em um AVA: o ROODAPlayer. Esta funcionalidade tem por objetivo ser uma ferramenta facilitadora na utilização de música, áudio e vídeo no contexto educacional. Atualmente o ROODAPlayer encontra-se em fase de testes na plataforma de desenvolvimento ROODA, disponível apenas na rede interna da Universidade.

Assim, as reflexões aqui apresentadas fazem parte de projeto de pesquisa que envolve a produção e utilização de áudios e vídeos integrados a ambientes virtuais de aprendizagem. Abrem-se perspectivas para utilização e avaliação dessa ferramenta em cursos de graduação nas diversas áreas do conhecimento, bem como o mapeamento de habilidades desenvolvidas a partir dessa tecnologia.

\section{NOTAS DE TEXTO}

1- ROODAPlayer fez parte do projeto intitulado "Do roodAFETO ao MINERAfórum: produzindo recursos tecnológicos para o ambiente ROODA". Esse projeto foi financiado pela Secretaria de Educação à Distância (SEAD) da UFRGS e desenvolvido pela equipe do NUTED - Núcleo de Tecnologia Digital aplicada à Educação (http://www.nuted.ufrgs.br).

${ }^{2}$ Disponível em https://www.ead.ufrgs.br/rooda/.

3- Disponível em:

https://spreadsheets.google.com/viewform?formkey=dDFYSVIOU0Y4TFVvdjNHSEh2 WIN6aFE6MQ.

\section{REFERÊNCIAS BIBLIOGRÁFICAS}

BEHAR, P. e Col. Modelos Pedagógicos em Educação a Distância. Ed. Artmed, Porto Alegre, Brasil. 2009.

BEHAR, P.; BERNARDI, M.; FROZI, A. P. e KELLEN, K. 2007. ROODA:

Desenvolvimento, Implementação e Validação de um AVA para a UFRGS. Taller

Internacional de Software Educativo. TISE - Santiago, Chile, 4 a 6 Dez de 2007. Disponível em: <http://www.tise.cl/archivos/tise2007/18.pdf>. Acesso em: 07 de mar. 2011.

BOTTENTUIT JUNIOR. J. B., LISBÔA, E. S. e COUTINHO, C. P. Podcast e Vodcast: o potencial da ferramenta VoiceThread. In: Carvalho, A. A. A. (Org). Actas do Encontro sobre Podcasts. Braga: CIEd. P.281- 286. 2009.

BOTTENTUIT JUNIOR, J. B. e COUTINHO, C. P. Podcast em Educação: um contributo para o estado da arte. In: Barca, A.; Peralbo, M.; Porto, A.; Silva, B.D. \& Almeida L. (eds.). Actas do IX Congresso Internacional Galego Português de Psicopedagogia. Setembro, A Coruña: Universidade da Coruña, 837-846. 2007. Disponível em: <http://repositorium.sdum.uminho.pt/bitstream/1822/7094/1/pod.pdf>. Acesso em: 11 de mar. 2011. 
CARDOSO, S. H. Memória: O Que é e Como Melhorá-la. In.: Revista Cérebro \& Mente. São Paulo. 1997.

CARLINI, A. L. e TARCIA, R. M. 2010. $20 \%$ a distância, e agora? Orientações práticas para o uso de tecnologia de educação a distância no ensino presencial. São Paulo: Pearson Education do Brasil.

CARVAlHO, A. A. A. (Org.). Actas do Encontro sobre Podcasts. Braga: CIEd.2009.

CASTRO, R. T. G. A afetividade e o desenvolvimento da aprendizagem.

Universidade Federal de Santa Maria, Santa Maria-RS. 2007. Disponível em:

<http://bibweb.si.ufsm.br/>. Acesso em: 13 mar. 2011.

CRUZ, S. C. 2009. O podcast no Ensino Básico. In.: Carvalho. A. A. A. (Org). Actas do Encontro sobre Podcasts. Braga: CIEd. P. 65-80. 2009.

GONZALEZ, M. Limites e possibilidades do áudio e do vídeo na educação.

Novembro, 2009. Disponível em: < http://www.artigonal.com/educacao-onlineartigos/limites-e-possibilidades-do-audio-e-do-video-na-educacao-1438425.html>. Acesso em: 13 mar. 2011.

HARGREAVES, D. Desenvolvimento musical e educação no mundo social. Centro de Investigação em Psicologia da Música e Educação Musical 9 CIPEM, n⿳01.

Novembro, 1999. Disponível em: < http://cipem.wordpress.com/revista/revista-1999n\%C2\%BA-1/>. Acesso em 20 mar. 2011.

LONGHI, M. T.; BEHAR, P. A. e BERCHT, M. AnimA-K: recognizing student's mood during the learning process. In: Sample Word Paper for Co-located Conferences at the $9^{\text {th }}$ WCC Congress. July, 27-31, Brazil, 2009. Disponível em: <http://www.wcce2009.org/proceedings/papers/WCCE2009_pap253.pdf>. Acesso em: 11 fev. 2011.

MARQUES, M. A. Formas de reforçar a mensagem áudio e de captar a atenção do ouvinte. In: Carvalho A. A. A. (Orga). Actas do Encontro sobre Podcasts. Braga: CIEd. P. 124- 132. 2009.

MCLOUGHLIN, C. \& LEE, M. Listen and learn: A systematic review of the evidence that podcasting supports learning in higher education. In.: C. Montgomerie \& J. Seale (Eds.). Proceedings of World Conference on Educational Multimedia, Hypermedia andTelecommunications. Chesapeake, VA: AACE. P. 1669-1677. 2007.

MOTA, J. C. G. de. Podcast - Pode o quê? In.: Carvalho. A. A. A. (Org). Actas do Encontro sobre Podcasts. Braga: CIEd. P. 309-312. 2009.

PIAGET. J. Estudos Sociológicos. Rio de Janeiro: Forense. 1973.

PRIMO, A. F. T. 2005. Para além da emissão sonora: as interações no podcasting. In:

Intexto. Porto Alegre, n. 13, 2005.

ROSAS, F. W. e BEHAR, P. A. A importância da música em objetos de aprendizagem. In: Anais do V Congresso Latino Americano de Objetos de Aprendizagem.

Universidade Mackenzie, São Paulo, Brasil, 2010. 